\title{
Cytomorphological and molecular diversity in backcross-derived inbred lines of sunflower (Helianthus annuus L.)
}

\author{
M. Sujatha, A.J. Prabakaran, Sangam L. Dwivedi, and S. Chandra
}

\begin{abstract}
A set of 250 distinct, stable, and uniform backcross-derived inbred lines were developed in sunflower through 5 interspecific cross combinations involving 4 wild diploid annual species (Helianthus argophyllus, H. petiolaris, H. annuus, and $H$. debilis). The presence of the wild-species genome in these inbred lines was confirmed through higher chromosome associations (tri- and quadrivalents) at diakinesis. Maximum structural rearrangements of chromosomes were observed in lines derived from $H$. petiolaris. Forty morphologically diverse inbred lines along with 2 controls were subjected to measurements of phenotypic and genetic distance using 118 simple sequence repeat (SSR) markers of known map location. A total of 204 alleles were identified and the number of alleles per locus varied between 2 and 5 . There were 46 unique alleles and the number of unique alleles was highest in the lines derived from the cross involving H. petiolaris. The polymorphism information content (PIC) values ranged from 0.05 to 0.575 . The pair-wise comparison values based on genetic dissimilarity estimates computed using molecular marker data varied between 0.143 and 0.486 among the 42 lines. The results indicate that the sunflower gene pool could benefit from introgression of novel alleles from the latent genetic diversity present in the wild species and particularly through exploitation of the diploid annual $\mathrm{H}$. petiolaris.
\end{abstract}

Key words: chromosome associations, diakinesis, diploid, Helianthus spp., genetic distance, interspecific hybridization, introgression, prebreeding, simple sequence repeats.

Résumé : Un jeu de 250 lignées fixées dérivées de retrocroisements, toutes différentes, stables et uniformes, ont été produites chez le tournesol par le biais de cinq croisements interspécifiques impliquant quatre espèces annuelles diploïdes sauvages $(H$. argophyllus, $H$. petiolaris, $H$. annuus et $H$. debilis). La présence d'ADN des espèces sauvages au sein de ces lignées fixées a été confirmée par l'observation d'associations chromosomiques, tels des tri- et quadrivalents, à la diacinèse. Les réarrangements structuraux les plus importants ont été observés chez les lignées dérivées de croisements impliquant le $H$. petiolaris. Sur la base de la diversité morphologique, 40 lignées fixées différentes et deux témoins ont fait l'objet d'analyses phénotypiques et de distance génétique, cette dernière à l'aide de 118 marqueurs SSR de position connue. Au total, 204 allèles ont été observés et le nombre d'allèles par locus variait entre 2 et 5 . Il y avait 46 allèles uniques et le plus grand nombre d'allèles uniques a été observé chez les lignées dérivées du croisement avec le H. petiolaris. L'indice de polymorphisme (PIC) variait entre 0,05 et 0,575. Les valeurs obtenues lors de la comparaison des paires de lignées sur la base des estimés de dissimilarité génétique, obtenus grâce aux marqueurs, variaient entre 0,143 et 0,486 parmi les 42 lignées. Ces résultats indiquent que le pool génique du tournesol pourrait bénéficier de l'introgression d'allèles nouveaux tirés de la diversité génétique latente présente au sein des espèces sauvages, particulièrement via l'exploitation de l'espèce diploïde annuelle $H$. petiolaris.

Mots-clés : associations chromosomiques, diacinèse, espèces diploïdes d'Helianthus, distance génétique, hybridation interspécifique, introgression, amélioration primaire, microsatellites.

[Traduit par la Rédaction]

\section{Introduction}

Worldwide, sunflower (Helianthus annuus L.) is fourth in importance as an oilseed after soybean, groundnut, rapeseed, and mustard and is grown on 23.4 million ha with a total annual production of 31.1 million tons and an average yield of $1.32 \mathrm{t} \mathrm{ha}^{-1}$ (FAO 2005). It is native to North America and has spread across the globe owing to its wide adaptability and short growing season. The commercial sunflower has a narrow genetic base and as a consequence only a few introductions constitute the base material for the development of new cultivars or hybrids. For example, only 10 to 12 introductions were used in India to develop new cultivars or hybrids (Sujatha et al. 2006).

Interspecific hybridization has played a pivotal role in the genetic improvement of sunflower (Korell et al. 1996). In-

Received 7 July 2007. Accepted 23 January 2008. Published on the NRC Research Press Web site at genome.nrc.ca on 13 March 2008.

Corresponding Editor: P. Gustafson.

M. Sujatha ${ }^{1}$ and A.J. Prabakaran. Directorate of Oilseeds Research, Rajendranagar, Hyderabad 500 030, India.

S.L. Dwivedi and S. Chandra. International Crops Research Institute for the Semi-arid Tropics, Patancheru, Hyderabad 502 324 , India.

${ }^{1}$ Corresponding author (e-mail: mulpurisujata@yahoo.com). 
terest in interspecific hybridization in sunflower is mainly for transfer of characters such as disease and insect resistance, salt tolerance, drought tolerance, fatty acid composition, protein quality, cytoplasmic male sterility, and fertility restoration. Use of related wild sunflower germplasm has allowed breeders to obtain resistance to numerous diseases, develop several cytoplasmic sources, and increase seed and oil yields (Korell et al. 1996). Forty-nine wild Helianthus species are available, which fall into 2 growth habit groups (annual and perennial) and 3 ploidy groups (diploid, tetraploid, and hexaploid). Among these, the diploid annuals constitute the primary gene pool and are mostly crosscompatible with cultivated sunflower.

The need to broaden the genetic base of cultivar germplasm, break the yield stagnation, develop material for diverse situations, and introgress specific characters from wild Helianthus species raised the interest in a pre-breeding programme in India. The backcross-derived inbred lines exhibited wide variability in terms of several distinct phenotypic characters not present in the parental species used. For example, the following lines were identified and stabilized: appressed plant types with an acute leaf angle giving a cauliflower type of appearance to the plant, lines with high leaf area index, early-maturing tall and dwarf types, latematuring tall and dwarf types, and lines with dense and sparse arrangement of leaves, small to very large leaves, small to large heads, short and long internodes, pigmented stems, and pale green to dark green leaves with variations in lamina structure. The stable pre-breeding materials developed using diploid annuals are serving as a source of maintainers or restorers for different cytoplasms and a source of resistance to rust and downy mildew, and represent material of interest for utilization in the sunflower breeding programme (Sujatha and Prabakaran 2004; Sujatha 2006). Pre-breeding material is generally selected and incorporated into breeding programmes based on morphological variation. While the value of morphological traits for evaluation varies according to the intended use of the material, knowledge of the level of genetic diversity in the pre-breeding material is important for selection of parental materials that can maximize the gain from selection.

In sunflower, several marker systems have been employed for assessment of genetic diversity in cultivated germplasm and wild sunflowers. Allozyme and RAPD polymorphisms were insufficient for distinguishing between closely or distantly related germplasm accessions in sunflower (Rieseberg and Seiler 1990; Rieseberg et al. 1993; Arias and Rieseberg 1995). Genetic diversity in wild and cultivated sunflower has been assessed using molecular markers such as RFLPs (Berry et al. 1994; Gentzbittel et al. 1994), AFLPs (Peerbolte and Peleman 1996; Gedil et al. 2001), and microsatellites (Dehmer and Friedt 1998; Yu et al. 2002; Burke et al. 2002; Tang et al. 2002, 2003; Tang and Knapp 2003). Berry et al. (1994), Gentzbittel et al. (1994), Rieseberg et al. (1993), and Arias and Rieseberg (1995) assessed allelic diversity in elite inbred lines using RFLPs and RAPDs, and DNA marker polymorphism rates ranged from $10 \%$ to $36 \%$ per cross. Sunflower-specific simple sequence repeats (SSRs) are informative, highly reproducible, and demonstrate a high degree of allelic variation (Yu et al. 2002, Burke et al. 2002; Tang et al. 2002, 2003; Tang and Knapp
2003). The abundance, codominant nature, high level of polymorphism, ready transferability, and ease of genotyping of SSRs make them an excellent molecular system for genetic diversity analysis. A total of 2968 SSR markers, including 1707 mapped markers, are available for molecular breeding and genomics research in sunflower.

The aim of the present study was to characterize advanced-generation lines derived from interspecific hybrids for cytomorphological relationships at diakinesis and to assess the genetic diversity to identify divergent lines for use in sunflower breeding programmes.

\section{Materials and methods}

\section{Plant material}

The plant material for this study was derived from interspecific hybrids between cultivated and wild diploid annual sunflowers, viz., $H$. annuus (wild), $H$. argophyllus, $H$. petiolaris, and $H$. debilis. Tri-species hybrids involving $H$. argophyllus and $H$. annuus with a sunflower cultivar $(H$. annuus 'Morden') were aimed at combining desirable traits such as rust and downy mildew resistance from the two diploid wild species with improved oil quality, yield, and other traits of agronomic value from cultivated sunflower. Branching and purple disc are undesirable traits in commercial sunflower and hence selection was done against these traits in each generation after a limited number of backcrosses with the cultivar as the recurrent pollen parent. A large number of lines with distinct phenotypes and other desirable traits have been selected, and the stabilized lines in the advanced generation are maintained through sib-mating.

\section{Phenotypic evaluation}

Forty backcross-derived inbred lines were selected from 250 lines based on initial diversity analysis of quantitative characters evaluated for 2 years. The 250 lines were initially subjected to cluster analysis based on Euclidian distance and the 40 most divergent lines were selected, representing $15 \%$ diversity from each cluster. Euclidian distance is the shortest geometric distance between two points in multidimensional space and is computed as

$$
\operatorname{distance}(x, y)=\left[\Sigma_{i}\left(x_{i}-y_{i}\right)^{2}\right]^{1 / 2}
$$

The pedigree and morphological characteristics of the inbred lines are presented in Table 1 . The 40 advanced lines and the 2 controls (Morden and CO-4) were grown in a $6 \times$ 7 rectangular lattice with 3 replications. Morden is an earlyflowering dwarf variety, while CO-4 is a medium-duration tall variety. A plot size of 4 rows of $4.2 \mathrm{~m}$ was adopted, with $0.60 \mathrm{~m}$ between rows and $0.30 \mathrm{~m}$ between plants within a row. Observations of 9 quantitative traits (days to flowering, days to $100 \%$ flowering, leaf chlorophyll (measured using a SPAD meter), plant height $(\mathrm{cm})$, head diameter $(\mathrm{cm})$, seed yield (g/plant), 100 seed mass $(\mathrm{g})$, stem mass $(\mathrm{g})$, and oil content (\%)) and 14 qualitative traits (head angle at maturity; head size and shape; stem pigmentation and thickness; leaf size, shape, margin, base, and colour; petiole type and leaf habit of petiole; ray floret colour and shape) were recorded following IPGRI (1985) descriptors and Ranganatha et al. (2007). 
Table 1. Morphological characteristics and pedigree of the prebred sunflower lines used in molecular characterization with microsatellite markers.

\begin{tabular}{|c|c|c|}
\hline PS No. & Pedigree & Morphological characters \\
\hline 1014 & $\mathrm{BC}_{4} \mathrm{~F}_{8}$ of $H$. argophyllus $\times$ Morden & Early flowering, medium height, high leaf area index (LAI) \\
\hline 1018 & $\mathrm{BC}_{4} \mathrm{~F}_{8}$ of $H$. argophyllus $\times$ Morden & Medium height, thick stem, long internodes \\
\hline 1028 & $\mathrm{BC}_{4} \mathrm{~F}_{8}$ of $H$. argophyllus $\times$ Morden & Deeply serrated leaf, early, small leaves \\
\hline 1041 & $\mathrm{BC}_{4} \mathrm{~F}_{8}$ of $H$. argophyllus $\times$ Morden & Late flowering, small leaves, deeply serrated and many fewer leaves \\
\hline 1053 & $\mathrm{BC}_{4} \mathrm{~F}_{8}$ of $H$. argophyllus $\times$ Morden & Short \\
\hline 1068B & $\mathrm{BC}_{4} \mathrm{~F}_{8}$ of $H$. argophyllus $\times$ Morden & Medium, better plant type, sparse arrangement of leaves, large heads, less susceptible to Alternaria \\
\hline 1082 & $\mathrm{BC}_{4} \mathrm{~F}_{8}$ of $H$. argophyllus $\times$ Morden & Normal, small but many leaves, deeply serrated leaves, thin stem \\
\hline 1084 & $\mathrm{BC}_{4} \mathrm{~F}_{8}$ of $H$. argophyllus $\times$ Morden & Thick stem, medium tall \\
\hline 1088 & $\mathrm{BC}_{4} \mathrm{~F}_{8}$ of $H$. argophyllus $\times$ Morden & Medium tall, deeply serrated leaves \\
\hline 1091 & $\mathrm{BC}_{4} \mathrm{~F}_{8}$ of $H$. argophyllus $\times$ Morden & Medium, large round leaves, long internodes, thick stem \\
\hline 44 & $\mathrm{BC}_{4} \mathrm{~F}_{8}$ of $H$. petiolaris $\times$ Morden & Short, high LAI \\
\hline 73 & $\mathrm{BC}_{4} \mathrm{~F}_{8}$ of $H$. petiolaris $\times$ Morden & Tall, long internodes \\
\hline 2001 & $\mathrm{BC}_{4} \mathrm{~F}_{8}$ of $H$. petiolaris $\times$ Morden & Short and fewer leaves, dwarf, early \\
\hline 2005 & $\mathrm{BC}_{4} \mathrm{~F}_{8}$ of $H$. petiolaris $\times$ Morden & Thick stem, tall, high LAI with large leaves, linear ray florets \\
\hline 2011 & $\mathrm{BC}_{4} \mathrm{~F}_{8}$ of $H$. petiolaris $\times$ Morden & Tolerant to rust \\
\hline 2013 & $\mathrm{BC}_{4} \mathrm{~F}_{8}$ of $H$. petiolaris $\times$ Morden & Zigzag and wavy stem, ovate leaves, lodging susceptible, early \\
\hline 2014 & $\mathrm{BC}_{4} \mathrm{~F}_{8}$ of $H$. petiolaris $\times$ Morden & Thick stem, tall, large leaves \\
\hline 2020 & $\mathrm{BC}_{4} \mathrm{~F}_{8}$ of $H$. petiolaris $\times$ Morden & Prominent venation of the leaf, tall, long petiole, sparsely arranged leaves \\
\hline 2033 & $\mathrm{BC}_{4} \mathrm{~F}_{8}$ of $H$. petiolaris $\times$ Morden & Round cup-shaped leaves, long internodes \\
\hline 2038 & $\mathrm{BC}_{4} \mathrm{~F}_{8}$ of $H$. petiolaris $\times$ Morden & Medium tall, stem-bending type \\
\hline 2046 & $\mathrm{BC}_{4} \mathrm{~F}_{8}$ of $H$. petiolaris $\times$ Morden & Tall, thick stem, large leaves \\
\hline $2047 \mathrm{a}$ & $\mathrm{BC}_{4} \mathrm{~F}_{8}$ of $H$. petiolaris $\times$ Morden & Large thick leaves, high LAI and clustering, dense arrangement of leaves \\
\hline 2048 & $\mathrm{BC}_{4} \mathrm{~F}_{8}$ of $H$. petiolaris $\times$ Morden & Early flowering \\
\hline 2058 & $\mathrm{BC}_{4} \mathrm{~F}_{8}$ of $H$. petiolaris $\times$ Morden & Tall, large leaves, medium thick stem, peculiar leaf arrangement \\
\hline 2062 & $\mathrm{BC}_{4} \mathrm{~F}_{8}$ of $H$. petiolaris $\times$ Morden & Dark green crinkled leaf, normal height, thick stem \\
\hline 3004 & $\mathrm{BC}_{3} \mathrm{~F}_{8}$ of $H$. annuus (wild) $\times$ Morden & Dwarf, cauliflower type \\
\hline 3007 & $\mathrm{BC}_{3} \mathrm{~F}_{8}$ of $H$. annuus (wild) $\times$ Morden & Cauliflower type of leaf arrangement, late-maturing type \\
\hline 3009 & $\mathrm{BC}_{3} \mathrm{~F}_{8}$ of $H$. annuus (wild) $\times$ Morden & Cauliflower type of leaf arrangement \\
\hline 3036 & $\mathrm{BC}_{3} \mathrm{~F}_{8}$ of $H$. annuus $($ wild $) \times$ Morden & Tall, regularly serrated cordate leaf with pubescence and thick petiole \\
\hline 4015 & $\mathrm{BC}_{3} \mathrm{~F}_{8}$ of $(H$. argophyllus $\times H$. annuиs $($ wild $)) \times$ Morden & Early, fewer leaves, angle of flower head bending $>135^{\circ}$, short \\
\hline 4020 & $\mathrm{BC}_{3} \mathrm{~F}_{8}$ of $(H$. argophyllus $\times H$. annuus (wild $\left.)\right) \times$ Morden & Normal, fewer leaves, pigmented petiole, not very productive, thin stem, small heads \\
\hline 4022 & $\mathrm{BC}_{3} \mathrm{~F}_{8}$ of $(H$. argophyllus $\times H$. annuus (wild $\left.)\right) \times$ Morden & Medium height, thick leaf, slightly turned \\
\hline 4061 & $\mathrm{BC}_{3} \mathrm{~F}_{8}$ of $(H$. argophyllus $\times H$. annuus (wild) $) \times$ Morden & Betel vine leaf type, pale green, soft ovate leaves, capitula covered with upper leaves, short \\
\hline 4066 & $\mathrm{BC}_{3} \mathrm{~F}_{8}$ of $(H$. argophyllus $\times H$. annuus (wild $\left.)\right) \times$ Morden & Medium height, large leaves, optimum-size heads \\
\hline 4083 & $\mathrm{BC}_{3} \mathrm{~F}_{8}$ of $(H$. argophyllus $\times H$. annuus (wild) $) \times$ Morden & Light green leaves, tall, late maturing, large leaves, long petiole, tree-type appearance \\
\hline 4093 & $\mathrm{BC}_{3} \mathrm{~F}_{8}$ of $(H$. argophyllus $\times H$. annuus (wild $\left.)\right) \times$ Morden & Tall, high LAI, long thick petioles, thick stem \\
\hline 4096 & $\mathrm{BC}_{3} \mathrm{~F}_{8}$ of $(H$. argophyllus $\times H$. апnиus (wild) $) \times$ Morden & Round ray florets, soft leaf, less serrated, spiral phyllotaxy, small heads, less susceptible to Alternaria \\
\hline 4111 & $\mathrm{BC}_{3} \mathrm{~F}_{8}$ of $(H$. argophyllus $\times H$. annuus (wild) $) \times$ Morden & Short, fewer leaves, late maturity \\
\hline 4114 & $\mathrm{BC}_{3} \mathrm{~F}_{8}$ of $(H$. argophyllus $\times H$. апnииs (wild $\left.)\right) \times$ Morden & Medium, large cup-shaped leaves \\
\hline 5016 & $\mathrm{BC}_{4} \mathrm{~F}_{8}$ of $\mathrm{CMS} 234 \mathrm{~A} \times H$. debilis & Restorer for $H$. argophyllus cytoplasm. Highly uniform, small leaves, typical head position, wavy leaf, late maturity \\
\hline Morden & Open-pollinated variety & Dwarf, early-maturing variety \\
\hline $\mathrm{CO}-4$ & Open-pollinated variety & Medium duration, medium-tall variety \\
\hline
\end{tabular}


Table 2. Meiotic chromosome associations at diakinesis of backcross-derived inbred lines of sunflower.

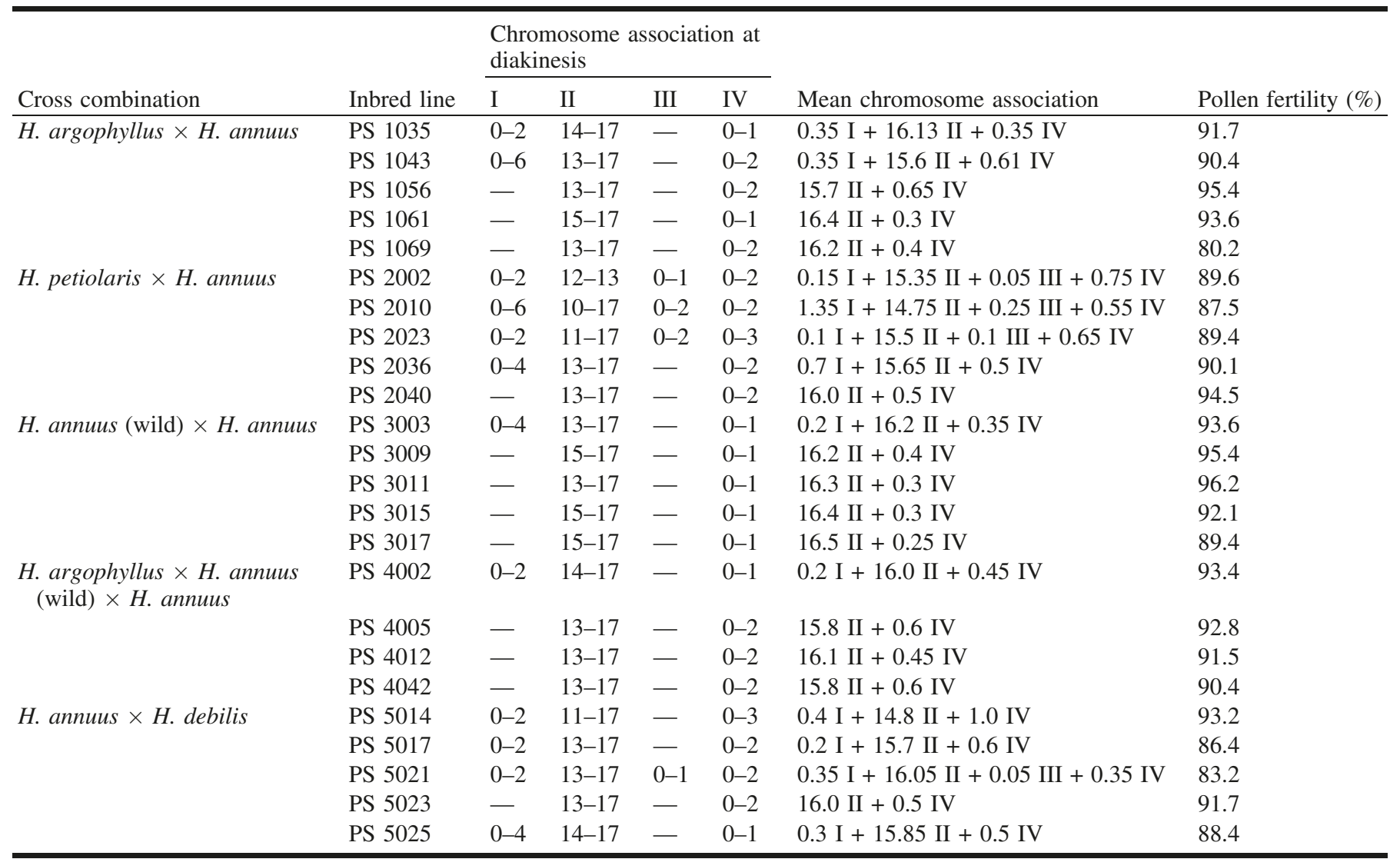

\section{Cytology}

For cytological analysis, 24 prebred lines comprising 4 or 5 lines from each of the cross combinations were used. Young flower buds of appropriate size were fixed in Carnoy's II solution (6:3:1 absolute ethanol : chloroform : glacial acetic acid) for $24 \mathrm{~h}$ and stored in $70 \%$ alcohol at $4{ }^{\circ} \mathrm{C}$. Pollen mother cell (PMC) smears were prepared using 1\% acetocarmine, and chromosomal associations of at least 100 PMCs were recorded after destaining the slides with $45 \%$ acetic acid. For study of pollen fertility, pollen was stained in a 1:1 mixture of $1 \%$ acetocarmine and glycerol. The fully stained and round pollen grains were scored as fertile, while shriveled and unstained grains were recorded as sterile.

\section{DNA extraction and SSR analysis}

For each line, leaves were harvested from 20 field-grown 6-week-old plants and bulked for DNA isolation. DNA was extracted following the CTAB method (Webb and Knapp 1990) and quantified on $0.8 \%$ agarose using a known concentration of $\lambda$ DNA as standard.

Using information on marker distribution on a genetic linkage map, 98 SSR primers of the ORS series (Knapp 2004) and 20 SSRs from Paniego et al. (2002) were selected. Polymerase chain reaction (PCR) was performed according to $\mathrm{Yu}$ et al. (2002). The codes for the ORS series were the original codes, while the SSRs of Paniego et al. (2002) were designated SF1 to SF20. The reaction mix $(20 \mu \mathrm{L})$ contained $20 \mathrm{ng}$ of DNA template, $5.5 \mathrm{pmol}$ of each primer, $2.5 \mathrm{mmol} / \mathrm{L} \mathrm{MgCl}_{2}, 125 \mu \mathrm{mol} / \mathrm{L}$ each $\mathrm{dNTP}$,
$1 \times$ PCR buffer, and $0.8 \mathrm{U}$ of Taq DNA polymerase (Genei, Bangalore, India). The PCR amplification profile included an initial denaturation step at $94{ }^{\circ} \mathrm{C}$ for $2 \mathrm{~min}$, followed by 45 cycles of denaturation at $94{ }^{\circ} \mathrm{C}$ for $30 \mathrm{~s}$, annealing for $30 \mathrm{~s}$, and extension at $72{ }^{\circ} \mathrm{C}$ for $1 \mathrm{~min}$, with a final extension at $72{ }^{\circ} \mathrm{C}$ for $5 \mathrm{~min}$ in a GeneAmp PCR System 9700 thermocycler (Perkin Elmer - Applied Biosystems). Annealing temperature varied between 51 and $60{ }^{\circ} \mathrm{C}$ for the primers used. The PCR-amplified products were run on $3.5 \%$ agarose (Genei, Bangalore, India) in $1 \times$ Tris-acetate EDTA buffer with ethidium bromide $(50 \mathrm{ng} / \mathrm{mL})$ for $2 \mathrm{~h}$ at $70 \mathrm{~V}$ for detection of allelic variations. A 50/100 bp ladder was used for measuring the allele size and an accurate size was determined using Quantity One software (Bio-Rad).

\section{Data analysis}

Presence or absence of a fragment was coded in a binary data matrix as 1 or 0 , respectively. In the case of primers revealing more than one allele, PCR amplifications were repeated. A band was considered unique if it was present in one line but absent in the remaining genotypes. Pair-wise genetic similarities $\left(S_{i j}\right)$ between accessions $i$ and $j$ were estimated using the similarity coefficient of Nei and Li (1979), $S_{i j}=2 N_{i j} /\left(N_{i}+N_{j}\right)$, where $N_{i j}$ is the number of bands in common between any two accessions and $S_{i j}$ may range from 0 (no common bands) to 1 (identical band profiles for the two accessions). $S_{i j}$ values were used to estimate genetic dissimilarity $\left(D_{i j}=1-S_{i j}\right)$, and the $D_{i j}$ values were used to determine the relationships among accessions using principal 
coordinate analysis (PCoA) (Sneath and Sokal 1973). The polymorphism information content (PIC) was calculated according to Botstein et al. (1980):

$$
\mathrm{PIC}=1-\sum_{i=1}^{k} p_{i}{ }^{2}-\sum_{i=1}^{k-1} \sum_{j=i+1}^{k} 2 p_{i}{ }^{2} p_{j}{ }^{2}
$$

where $k$ is the number of alleles for a given marker and $p_{i}$ and $p_{j}$ are the allelic frequencies. The Mantel test of significance was used to determine the goodness of fit for the correlation between phenotypic traits and molecular data. All computations were performed using the statistical computing package GenStat release 6.1 (Payne 2002) and NTSYS pc version 2.20 (Applied Biostatistics Inc., Setauket, New York). For association mapping, multidimensional scaling was carried out in NTSYS pc for the 42 inbred lines based on morphological data, and stepwise regression analysis was carried out in GenStat using the phenotypic data.

\section{Results}

\section{Cytomorphological diversity}

We were interested to know the influence of leftover wild genome in the stabilized lines on meiotic chromosome pairing and pollen fertility. Diakinesis is the ideal stage for the study of chromosome associations. Irrespective of the cross combination, the backcross-derived inbred lines showed normal meiosis in 50\%-70\% of the PMCs and formation of 17 bivalents (Table 2). Among the several bivalent shapes, ring, rod, and open-ring bivalents occurred more frequently than other configurations such as ' 8 ', ' $\mathrm{V}$ ', loose chain, or bracket (Fig. 1). The inbred lines frequently showed the presence of quadrivalents in addition to normal bivalents. Quadrivalents were observed in all the lines at frequencies ranging from 1 to 3 (Table 2; Fig. 1). Among the 24 prebred lines, several showed two quadrivalents during diakinesis. In contrast, a third quadrivalent was reported in PS 2023 and PS 5014. The lines PS 2010, PS 2023, PS 2002, and PS 5021 occasionally showed trivalents during meiosis. In this study, the frequency of univalents ranged from 0 to 6 , with lines PS 1043 and PS 2010 showing up to 6 univalents during diakinesis. Many lines showed pollen fertility comparable with that of cultivated sunflower, while a few lines, such as PS 1069 , showed low pollen fertility $(80.2 \%)$.

\section{Molecular characterization}

Of the 118 SSR primers tested, 100 produced 204 amplicons of the expected size, of which 199 (97.5\%) were polymorphic. The primers ORS333, ORS334, ORS378, and ORS396 failed to produce amplification products; ORS163, ORS237, ORS244, ORS328, ORS447, and SF15 produced multiple bands that were difficult to interpret; ORS200, ORS240, ORS257, and ORS426 failed to produce amplicons of reference allele size; and ORS235, ORS258, ORS295, and ORS384 produced monomorphic bands. The number of alleles per locus ranged from 2 to 5 (Fig. 2). The PIC for polymorphic SSRs ranged from 0.05 to 0.575 , with an average of 0.31 (Table 3). ORS169, SF11, and SF14 generated a maximum of 5 alleles. The polymorphic microsatellites produced an average of 2.04 alleles/locus.
Fig. 1. Chromosome associations observed at diakinesis in backcross-derived inbred lines of sunflower: (a) 17 II in PS 3017, (b) $16 \mathrm{II}+2$ I in PS 1043, (c) $3 \mathrm{IV}+11 \mathrm{II}$ in PS 5014, (d) $1 \mathrm{IV}+$ $14 \mathrm{II}+2 \mathrm{I}$ in PS 3003, (e) $3 \mathrm{IV}+1 \mathrm{III}+9 \mathrm{II}+1 \mathrm{I}$ in PS 2023,

(f) $3 \mathrm{IV}+10 \mathrm{II}+2 \mathrm{I}$ in PS 5014, $(\mathrm{g}) 2 \mathrm{IV}+13$ II in PS 1056, and (h) 3 IV + 9 II + 4 I in PS 2023.
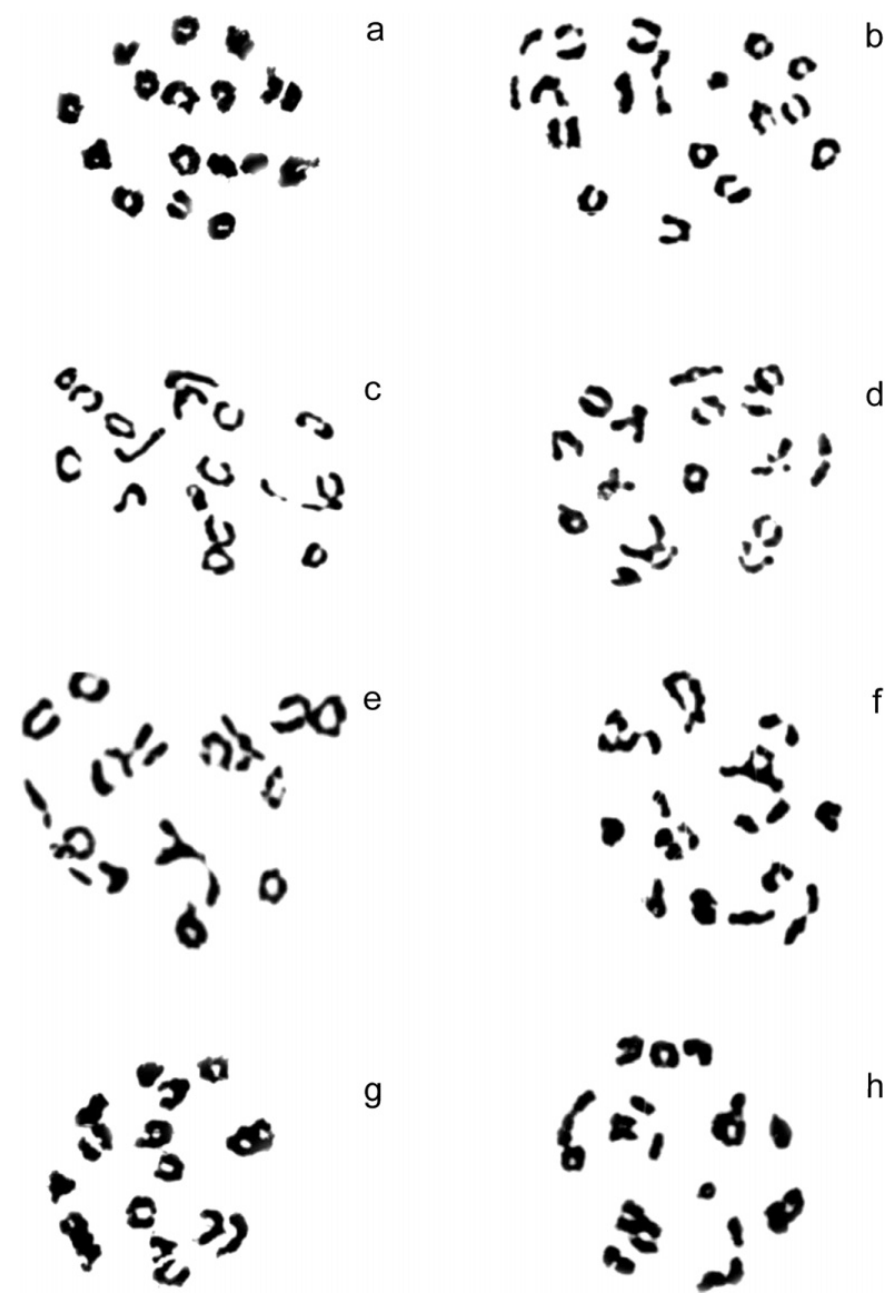

g

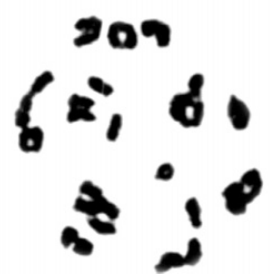

Unique alleles

Of the 118 tested pairs of primers, 27 produced 46 unique alleles in 18 inbred lines (Table 4). Each of these 27 markers could distinguish 1 to 3 alleles. The marker ORS256 could distinguish 4 genotypes, detecting unique alleles in 2 inbred lines derived from the cross involving H. petiolaris (PS 2047a and PS 2048) and 2 lines derived from the trispecific cross (PS 4022 and PS 4066).

Preliminary data on the utility of SSRs for trait association analysis (Table 5) revealed positive and significant association of microsatellites with traits such as days to flowering and head diameter. The microsatellite marker SF $2_{153}$ was found to be significantly and positively correlated with days to flowering.

The genetic dissimilarity $\left(D_{i j}\right)$ among the 42 lines ranged from 0.143 to 0.486 , with an average of 0.311 (Table 6). The maximum genetic distance based on molecular characterization was found between PS 2020 and PS 1053 and between PS 4066 and PS 2048, while the genetic distance between the two commercial genotypes (CO-4 and Morden) 
Fig. 2. Allelic variation in backcross-derived inbred lines of sunflower with SSR primer ORS202 (M, 100 bp DNA ladder; 1-42, samples). M 1

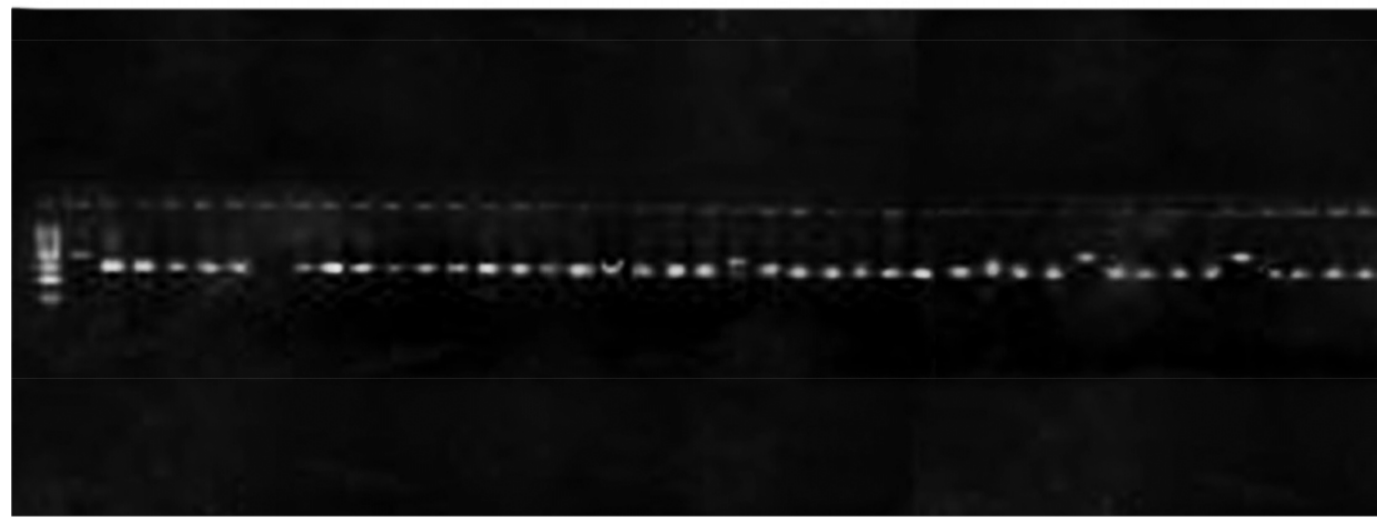

Table 3. PIC values for selected SSR primers.

\begin{tabular}{llll}
\hline Primer & PIC & Primer & PIC \\
\hline ORS12 & 0.5006 & ORS358 & 0.1886 \\
ORS31 & 0.5013 & ORS364 & 0.1737 \\
ORS70 & 0.1623 & ORS366 & 0.1351 \\
ORS90 & 0.5068 & ORS351 & 0.0526 \\
ORS123 & 0.5011 & ORS372 & 0.3556 \\
ORS124 & 0.5747 & ORS391 & 0.0908 \\
ORS134 & 0.3926 & ORS418 & 0.5392 \\
ORS142 & 0.4860 & ORS426 & 0.4791 \\
ORS151 & 0.4702 & ORS462 & 0.4441 \\
ORS154 & 0.5095 & ORS468 & 0.1141 \\
ORS166 & 0.132 & ORS481 & 0.5035 \\
ORS169 & 0.5649 & ORS485 & 0.0714 \\
ORS170 & 0.4277 & SF2 & 0.1505 \\
ORS176 & 0.3704 & SF3 & 0.1726 \\
ORS185 & 0.0597 & SF4 & 0.1028 \\
ORS187 & 0.1024 & SF5 & 0.3869 \\
ORS188 & 0.4805 & SF6 & 0.4261 \\
ORS200 & 0.0635 & SF7 & 0.1999 \\
ORS202 & 0.2369 & SF10 & 0.4442 \\
OR6216 & 0.0667 & SF11 & 0.2149 \\
ORS243 & 0.3669 & SF13 & 0.5098 \\
ORS256 & 0.1786 & SF14 & 0.3426 \\
ORS307 & 0.5057 & SF16 & 0.2571 \\
ORS317 & 0.3075 & SF19 & 0.1382 \\
ORS344 & 0.2182 & SF20 & 0.0455 \\
\hline
\end{tabular}

was low. The mean genetic distance based on morphological characteristics (pooled for the dry and rainy seasons) between a specific line and the other 41 lines ranged from 0.006 to 0.395 . The genetic distance based on phenotypic evaluation was low for PS $2062 \times$ PS 2005 and maximum for PS $4083 \times$ PS 4015 . The most diverse inbred lines were PS $2048(\check{D}=0.406)$ and PS $1053(\check{D}=0.403)$, while PS $1091(\check{D}=0.258)$ showed the least diversity. Morphologically the lines diverged at 0.84 similarity, while at the molecular level they separated at a distance of 0.59 .

Cluster analysis and principal coordinate analysis did not reveal distinct groupings. The clustering pattern based on molecular marker-based genetic distances was not significantly correlated with that based on morphological characters. A dendrogram based on the data pooled from the phenotypic and molecular analyses separated the lines into 4 clusters, and lines PS 4083 and PS 4093 (high LAI and tall, tree-like appearance) formed a distinct cluster (Fig. 3). Line PS 3009 has a cauliflower type of appearance, PS 4061 has a pale green betel vine type of leaves, and PS 4083 and PS 4093 have a small tree-like appearance with thick stems and densely arranged large dark green leaves. The correlation between the phenotypic traits and molecular data based on the Mantel statistic was not significant $(r=$ $0.08860)$.

\section{Discussion}

The genomes of the diploid annual wild sunflowers constituting the primary gene pool are considered not similar but closely related to that of cultivated sunflower (Chandler et al. 1986). Higher chromosome associations such as trivalents and quadrivalents during meiosis have been reported in $\mathrm{F}_{1}$ interspecific hybrids involving cultivated and wild diploid species of Helianthus (Whelan 1979; Whelan and Dorrell 1980; Chandler et al. 1986; Narkhede et al. 1986). This led to the conclusion that the genomes of these species in the primary gene pool differ from each other by a limited number of reciprocal translocations.

Georgieva-Todorova (1984) considered autosyndesis of chromosomes to be the cause of ring bivalents and heteromorphic nature (formed by conjugation between homoeologous chromosomes) to be the cause of more frequent rod bivalents. Exchange of unequal chromatin segments between nonhomologous chromosomes (translocation of chromosomes) may be a reason for the formation of quadrivalents (Chandler et al. 1986; Narkhede et al. 1986). A possible explanation for the differences between the present study and previous reports on interspecific hybrids of wild diploid species may be intraspecifc structural polymorphism. It is of interest that hybrids for which discrepancies exist involved either $H$. petiolaris or $H$. debilis as parent. Occasionally, secondary or nonhomologous association of chromosomes can give spurious results in the study of translocation heterozygosity in interspecific hybrids (Chandler et al. 1986). The presence of quadrivalents at the diakinesis stage in interspecific hybrids is well documented (Chandler et al. 1986). Narkhede et al. (1986) reported a single quadrivalent in the interspecific hybrid between sunflower and $\mathrm{H}$. argo- 
Table 4. Unique alleles in backcross-derived inbred lines of sunflower.

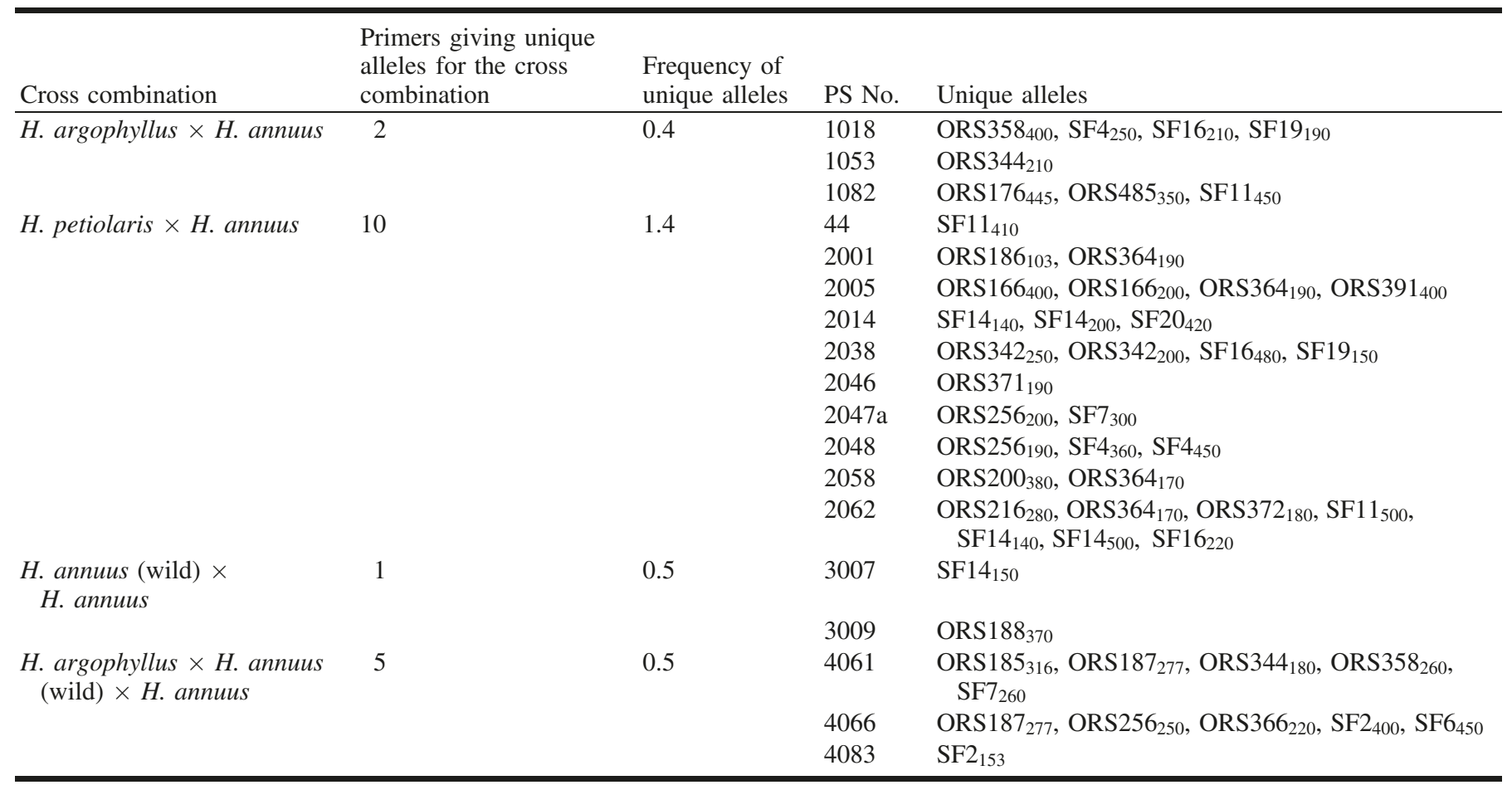

phyllus and 2 quadrivalents in the interspecific hybrid between $H$. annuus and $H$. debilis and suggested that the genomes differed by 1 and 2 reciprocal translocations, respectively. It is expected that interspecific hybrids will possess a genome contributed equally by the 2 parents in order to show multivalent configurations. But in recombinant inbred lines, after 2-3 backcrosses a significant portion of the wild genome is replaced by the cultivar genome; therefore, the chance of multivalent formation is reduced. However, the prebred lines, which are stabilized interspecific derivatives, also showed quadrivalents. Hence, it may be concluded that recombinant inbred lines developed through interspecific hybridization possess a very large spectrum of variability due to a high degree of recombination between nonhomologous chromosomes of the parental genomes, as revealed by the presence of 1-3 translocations.

The formation of trivalents may be attributed to loose or improper pairing of quadrivalents, which could lead to the dissociation of quadrivalents into one trivalent and a univalent (Narkhede et al. 1986). Chandler et al. (1986) considered secondary associations to be the cause of formation of univalents. Secondary associations occur when homologous pairing is incomplete in individuals such as haploids and interspecific hybrids. Since Helianthus is considered to have an ancient tetraploid origin, secondary associations may also be the source of univalent formation.

Reduced pollen fertility (80.2\%) in PS 1069 can be correlated with the high frequency of chromosome bridges and laggards that was observed in anaphase I. Reduced pollen fertility in interspecific hybrids has been reported (Georgieva-Todorova 1984; Narkhede et al. 1986; Espinasse et al. 1995). Since an interspecific hybrid has genomes from both parents, the presence of a wild genome in the hybrid is enough to cause meiotic irregularities that lead to reduced pollen fertility. However, continued backcrosses with cultivated sunflower eventually eliminate wild characters, and stabilization of meiosis should have occurred more rapidly, as reported in $H$. maximiliani $\times H$. annuus interspecific hybrids by Whelan and Dorrell (1980).

The number of alleles detected will depend on the diversity of the germplasm sampled and also on the informativeness of the marker or primer set. The PIC scores in this study were not significantly different from those reported earlier (0.17-0.49, Gedil 1999; 0.31-0.55, Yu et al. 2002). In the study of Paniego et al. (2002), the polymorphic microsatellites produced an average of 3.5 alleles/locus and an average PIC of 0.55 . This variation in PIC could be due to the limited number of microsatellites (100) used in our study, in contrast to the study of Paniego et al. (2002), in which 271 microsatellites were used. Furthermore, we checked the allelic variation on agarose gels with ethidium bromide staining, unlike the study of Paniego et al. (2002), where denaturing polyacrylamide gels with silver staining were used. Most studies of SSRs in sunflower have employed automated multiplex PCR using a multicolor assay based on fluorophores that reveal polymorphism more discretely (Burke et al. 2002; Tang et al. 2002; Yu et al. 2002).

Six primers produced multiple bands. Paniego et al. (2002) made a similar observation and attributed such complex patterns to the heterogeneity or heterozygosity of the inbred lines or the presence of 2 (or more) duplicated microsatellite loci. However, only 6 of the 118 microsatellites $(5.1 \%)$ tested in this study gave evidence of heterozygosity and (or) heterogeneity, suggesting a sufficient degree of inbreeding in the inbred lines analyzed in this study.

The present study reveals that microsatellites are useful not only in discriminating lines derived from the same pedigree but also in identification of unique alleles in backcross- 
derived inbred lines. Paniego et al. (2002) demonstrated the potential of SSR markers in identification of inbred lines of sunflower and assessment of their distinctness and genetic diversity. The presence of unique alleles is an indication of a high rate of genetic rearrangement. Unique alleles are significant because they can be diagnostic of a particular inbred line or regions of the genome specific to a particular type of genotype (Senior et al. 1998). The primer ORS256 could distinguish 4 genotypes in this study. This marker was highly polymorphic and had 15 alleles with a PIC score of 0.93 (Yu et al. 2002). The occurrence of the maximum number of unique alleles in the cross combination involving $H$. petiolaris indicates the potential of this species to serve as a reservoir of novel alleles for sunflower improvement. Cytological investigations carried out in the present study revealed a high degree of structural polymorphism, with a higher number of multivalents in interspecific hybrids involving $H$. petiolaris or $H$. debilis as parent. Helianthus petiolaris has been widely exploited as a source of sterile cytoplasm on which entire sunflower hybrid breeding programmes are based, and this study reveals the usefulness of this species in widening the genetic base of cultivated sunflower. The allelic diversity in the lines derived from the trispecific cross was low compared with that in lines derived from $H$. petiolaris. Although lines derived from crosses involving $H$. debilis showed a high degree of chromosomal rearrangements, not much information could be drawn from molecular characterization, as it involved only one line. Allelic diversity in Native American land races and wild populations of cultivated sunflower showed that wild populations are a wellspring of genetic diversity (Tang and Knapp 2003). Allelic diversity based on allozyme analysis revealed a higher number of unique alleles in wild populations than in domesticated sunflower (Rieseberg and Seiler 1990). Tang and Knapp (2003) found a gradual but dramatic (33-fold) narrowing of allelic diversity from taxon-specific alleles of the wild population to the elite inbred lines.

In this study, null alleles were detected. RFLP and SSR markers are rarely dominant in crop plants (Akkaya et al. 1992; Liu et al. 1996). However, several studies have proved that sunflower is an exception to this observation; these studies reported that $9 \%$ to $30 \%$ of the SSRs and RFLPs produced null alleles among elite inbred lines (Yu et al. 2002; Berry et al. 1994; Gentzbittel et al. 1994; Jan et al. 1998).

Cluster analysis and principal coordinate analysis were used for visualization of estimates of genetic distance. Cluster analysis of these lines revealed a lack of structure, and there were small clusters with no clear grouping. Presumably this could be due to differences in the pedigree of the lines and the selection of parents with contrasting and common traits, such as dwarf with early and late maturity, tall with both maturity groups, and so on. Most other genetic analyses have been based on market classes, fertility/restorer lines, and geographical entities (Yu et al. 2002).

The presence of a high degree of chromosomal rearrangements, the high frequency of unique alleles, and the maximum genetic distance revealed by these lines are indicative of the usefulness of $H$. petiolaris in introgressive breeding. The diverse genotypes of Argentine origin are also a result 
Table 6. Molecular and phenotypic diversity and trait differences among selected lines derived from interspecific hybrids of sunflower.

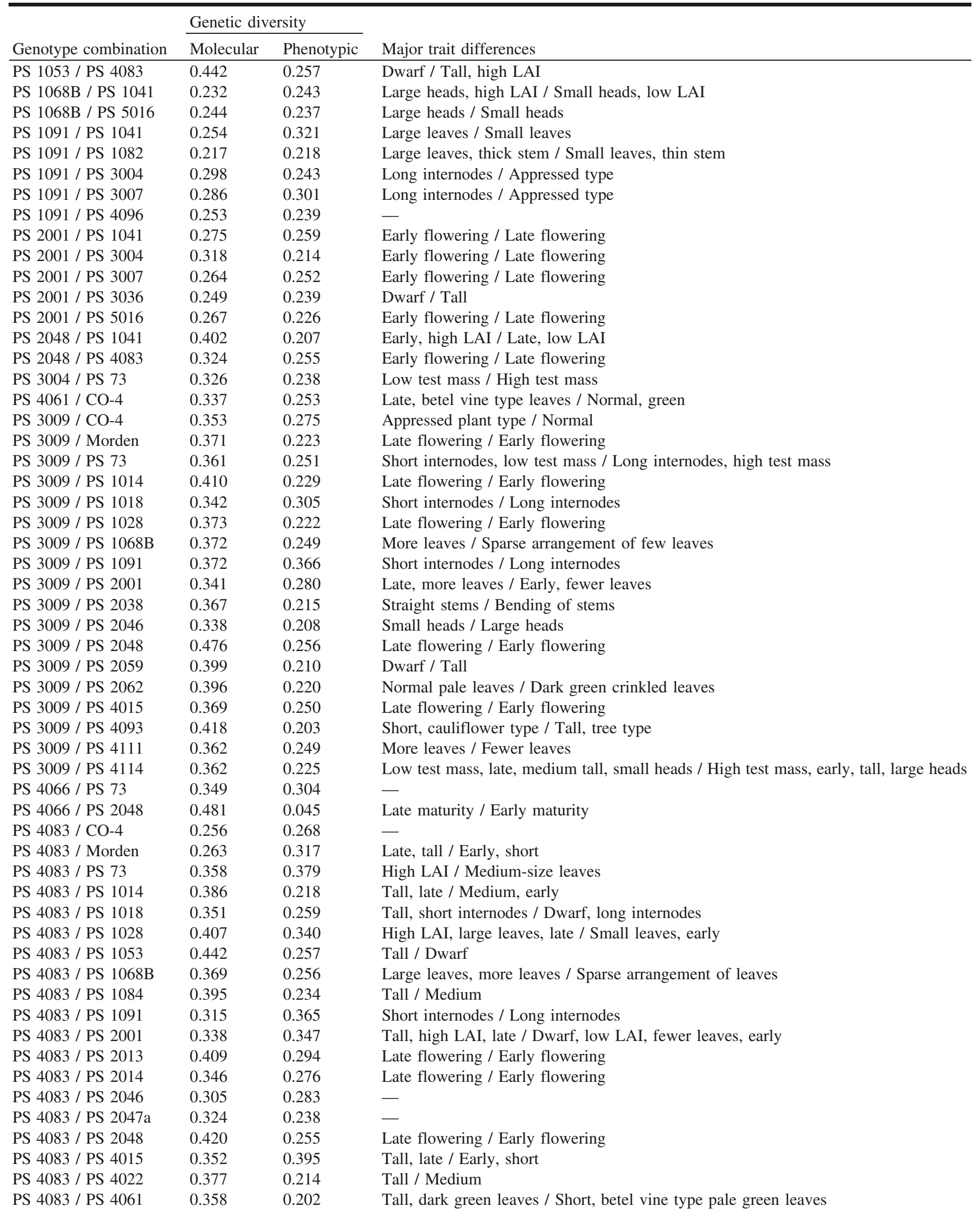


Table 6 (concluded).

\begin{tabular}{llll}
\hline & \multicolumn{2}{l}{ Genetic diversity } & \\
\cline { 2 - 3 } Genotype combination & Molecular & Phenotypic & Major trait differences \\
\hline PS 4083 / PS 4066 & 0.362 & 0.276 & Tall / Medium \\
PS 4083 / PS 4111 & 0.328 & 0.352 & Tall / Medium \\
PS 4083 / PS 4114 & 0.299 & 0.307 & Tall, late / Medium, early \\
PS 4083 / PS 5016 & 0.285 & 0.216 & Large leaves / Small leaves \\
PS 5016 / CO-4 & 0.250 & 0.254 & Small leaves / Medium leaves \\
PS 5016 / PS 73 & 0.253 & 0.231 & Low test mass, medium / High test mass, tall \\
PS 5016 / PS 1018 & 0.265 & 0.232 & High chlorophyll content, thin stem / Low chlorophyll content, thick stem \\
PS 5016 / PS 1068B & 0.244 & 0.237 & Low oil content, small heads / High oil content, large heads \\
PS 5016 / PS 1091 & 0.232 & 0.275 & Low oil content, high chlorophyll content, thin stem / High oil content, low chlorophyll \\
& & & content, thick stem \\
\hline
\end{tabular}

Fig. 3. Dendrogram of 40 backcross-derived inbred lines of sunflower along with 2 commercial cultivars (CO-4 and Morden) based on pooled genetic distance as measured by phenotypic variation in two seasons and allelic variation determined using SSR markers.

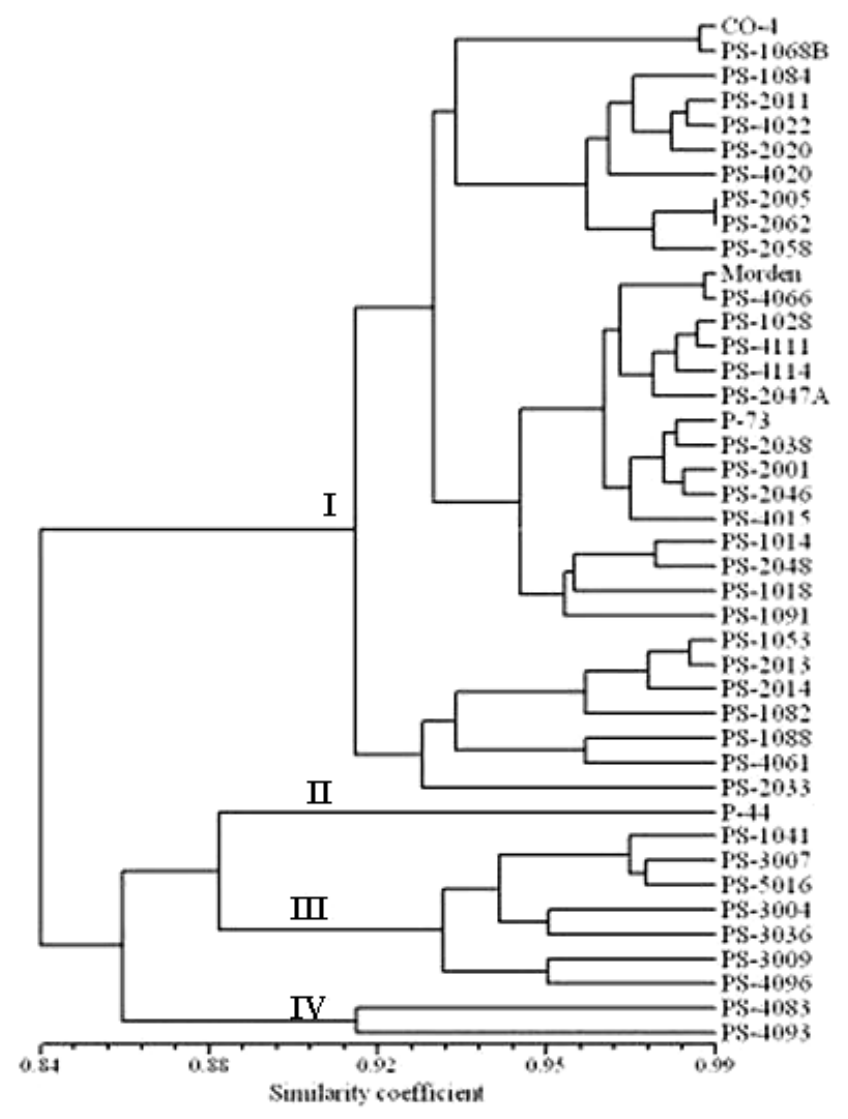

of intensive utilization of wide interspecific crossing with diploid annual sunflowers (Paniego et al. 2002).

The earlier genetic maps were constructed using $\mathrm{F}_{2}$ progeny from a cross between oilseed sterility maintainer lines, RILs from crosses within proprietory oilseed fertility restorer lines, and RILs from crosses between public confectionery and oilseed fertility restorer lines (Gedil 1999; Yu et al. 2002; Tang et al. 2002). The SSR markers placed on these three elite $\times$ elite cross maps represent the subset with the greatest utility for molecular breeding in the highly selected and domesticated gene pools on which the commercial hybrid breeding programmes are based. The materials used in the above-mentioned studies represent only part of the overall variability. The studies of Tang and Knapp (2003) and Burke et al. (2002) emphasize the need for use of progeny from elite $\times$ wild crosses to increase the density of the molecular genetic linkage map of sunflower, because allelic variability declines 33 -fold from wild to domesticated cultivars. In the present study we have identified several unique alleles in genotyping 42 lines with 118 SSR primers on agarose gels. There is a distinct possibility of identifying several unique alleles in the 250 lines developed if they are genotyped using a larger number of mapped SSR markers on semi-automated or automated systems to facilitate increasing the density of the genetic map.

For quantitative characters such as yield, heterotic response is expected to increase with parental genetic distance (Melchinger 1999). Use of backcross-derived lines facilitates the detection of linkages. Cytomorphological studies coupled with molecular characterization using mapped SSR markers can help to define the genetic architecture of the germplasm and to identify alleles associated with key phenotypic traits. This study shows that the molecular variation is high and the backcross-derived inbred lines with the same phenotype show high allelic diversity. The inbred lines in the present study were derived from interspecific crosses of diploid annual species. The lines were defined with chromosomal associations at diakinesis and microsatellite markers. This molecular diversity analysis will assist sunflower breeders in inbred line development and facilitate identification of well-defined heterotic groups. Further, all the stabilized inbred lines will be characterized using FISH techniques to demonstrate the extent of introgression in terms of the number and size of the introgressed fragments, according to Feng et al. (2005). The lines will also be subjected to molecular classification for identification of new sources of alleles for broadening the genetic base of sunflower.

\section{Acknowledgements}

The authors thank the Project Director, Directorate of Oilseeds Research, for providing the facilities for carrying out the research work and Ms. M. Tarakeswari for her technical help in SSR analysis.

\section{References}

Akkaya, M.S., Bhagwat, A.A., and Cregan, P.B. 1992. Length 
polymorphisms of simple sequence repeat DNA in soybean. Genetics, 132: 1131-1139. PMID:1459432.

Arias, D.M., and Rieseberg, L.H. 1995. Genetic relationships among domesticated and wild sunflowers (Helianthus annuus L. Asteraceae). Econ. Bot. 49: 239-248.

Berry, S.T., Allen, R.J., Barnes, S.R., and Caligari, P.D.S. 1994. Molecular marker analysis of Helianthus annuus L. 1. Restriction fragment length polymorphisms between inbred lines of cultivated sunflower. Theor. Appl. Genet. 89:.435-441.

Botstein, D., White, R.L., Skolnick, M., and Davis, R.W. 1980. Construction of a genetic linkage map in man using restriction fragment length polymorphisms. Am. J. Hum. Genet. 32: 314-331. PMID:6247908.

Burke, J.M., Tang, S., Knapp, S.J., and Rieseberg, L.H. 2002. Genetic analysis of sunflower domestication. Genetics, 161: 1257-1267. PMID:12136028.

Chandler, J.M., Jan, C.C., and Beard, B.H. 1986. Chromosome differentiation among the annual Helianthus species. Syst. Bot. 11: 354-371. doi: $10.2307 / 2419126$.

Dehmer, K.J., and Friedt, W. 1998. Evaluation of different microsatellite motifs for analyzing genetic relationships in cultivated sunflower (Helianthus annuus L.). Plant Breed. 117: 45-48. doi:10.1111/j.1439-0523.1998.tb01446.x.

Espinasse, A., Foueillasar, J., and Kimber, G. 1995. Cytogenetical analysis of hybrids between sunflower and four wild relatives. Euphytica, 82: 65-72. doi:10.1007/BF00028710.

FAO. 2005. ProdSTAT. Available from http://faostat.fao.org/site/ 567/default.aspx [accessed 26 May 2006].

Feng, J., Jan, C.C., Vick, B.A., and Zhang, H.-B. 2005. Construction of two sunflower (Helianthus annuus L.) BAC and BIBAC libraries and their application to fluorescence in situ hybridization (FISH). In Proceedings of the 27th Sunflower Research Workshop, Fargo, N.D., 12-13 January 2005. Available from http://www.sunflowernsa.com/research/research-workshop/ documents/Feng_BIBAC_05.PDF.

Gedil, M.A. 1999. Marker development, genome mapping, and cloning of candidate disease resistance genes in sunflower, Helianthus annuus L. Ph.D. thesis, Oregon State University, Corvallis.

Gedil, M.A., Wye, C., Berry, S.T., Seger, B., Peleman, J., Jones, R., et al. 2001. An integrated RFLP-AFLP linkage map for cultivated sunflower. Genome, 44: 213-221. doi:10.1139/gen-44-2-213. PMID:11341731.

Gentzbittel, L., Zhang, Y.-X., Vear, F., Griveau, B., and Nicolas, P. 1994. RFLP studies of genetic relationships among inbred lines of the cultivated sunflower, Helianthus annuus L.: evidence for distinct restorer and maintainer germplasm pools. Theor. Appl. Genet. 89: 419-425. doi:10.1007/BF00225376.

Georgieva-Todorova, J. 1984. Interspecific hybridization in the genus Helianthus L. Z. Pflanzenzuchtung, 93: 265-279.

IPGRI. 1985. Sunflower descriptors. Available from http://www. ipgri.cgiar.org/publications/HTMLPublications/261/index.htm.

Jan, C.C., Vick, B.A., Miller, J.F., Kahler, A.L., and Butler, E.T. 1998. Construction of an RFLP linkage map for cultivated sunflower. Theor. Appl. Genet. 96: 15-22. doi:10.1007/s001220050703.

Knapp, S.J. 2004. Simple sequence repeat (SSR) markers for cultivated sunflower (Helianthus annuus L.) developed from genomic DNA libraries. Available from http://cropandsoil.oregonstate. edu/knapp-lab/ [accessed 25 July 2004].

Korell, M., Brahm, L., Friedt, W., and Horn, R. 1996. Interspecific and intergeneric hybridization in sunflower breeding. II. Specific uses of wild germplasm. Plant Breed. Abstr. 66: 1081-1091.

Liu, Z.W., Biyashev, R.M., and Saghai Maroof, M.A. 1996. Development of simple sequence repeat DNA markers and their integration into a barley linkage map. Theor. Appl. Genet. 93: 869-876.

Melchinger, A.E. 1999. Genetic diversity and heterosis. In The genetics and exploitation of heterosis in crops. Edited by J.G. Coors and S. Pandey. CSSA, Madison, Wis. pp. 99-118.

Narkhede, M.N., Dharmraj, V., and Meshram, L.D. 1986. Meiotic studies in interspecific hybrids of Helianthus. Panjabrao Krishi Vidyapeeth Res. J. 10: 84-87.

Nei, M., and Li, W.H. 1979. Mathematical model for studying genetic variation in terms of restriction endonucleases. Proc. Natl. Acad. Sci. U.S.A. 76: 5269-5273. doi:10.1073/pnas.76.10. 5269. PMID:291943.

Paniego, N., Echaide, M., Munoz, M., Fernandez, L., Torales, S., Faccio, P., et al. 2002. Microsatellite isolation and characterization in sunflower (Helianthus annuus L.). Genome, 45: 34-43. doi:10.1139/g01-120. PMID:11908666.

Payne, R.W. 2002. The guide to GenStat ${ }^{\circledR}$ release 6.1. Part 2. Statistics. VSN International Ltd., Oxford, UK.

Peerbolte, R.P., and Peleman, J. 1996. The CARTISOL sunflower RFLP map (146 loci) extended with 291 AFLP markers. In Proceedings of the 18th Sunflower Research Forum, Fargo, N.D., 11-12 January 1996. National Sunflower Association, Bismarck, N.D. pp 174-178.

Ranganatha, A.R.G., Mukta, N., and Prabakaran, A.J. 2007. Sunflower (Helianthus annuus L.). In National guidelines for conduct of tests for distinctness, uniformity and stability. Directorate of Seed Research, Kushmaur, MAU, UP, India. pp. 197-208.

Rieseberg, L.H., Choi, H., Chan, R., and Spore, C. 1993. Genomic map of a diploid hybrid species. Heredity, 70: 285-293.

Rieseberg, L.H., and Seiler, G.J. 1990. Molecular evidence and the origin and development of the domesticated sunflower (Helianthus annuus, Asteraceae). Econ. Bot. 44: 79-91.

Senior, M.L., Murphy, J.P., Goodman, M.M., and Stuber, C.W. 1998. Utility of SSRs for determining genetic similarities and relationships in maize using an agarose gel system. Crop Sci. 38: $1088-1098$.

Sneath, P.H.A., and Sokal, R.R. 1973. Numerical taxonomy. W.H. Freeman and Co., San Francisco.

Sujatha, M. 2006. Wild Helianthus species used for broadening the genetic base of cultivated sunflower in India. Helia, 29: 77-86. doi:10.2298/HEL0644077S.

Sujatha, M., and Prabakaran, A.J. 2004. Prebreeding and altering the genetic architecture of Indian sunflowers using wild sunflowers. In Proceedings of the 16th International Sunflower Conference, Fargo, N.D., 29 August - 2 September 2004. Vol. II. pp. 755-760.

Sujatha, M., Ranganatha, A.R.G., Vishnuvardhan Reddy, A., and Lakshmi, P. 2006. Crop improvement. In Research achievements in sunflower. All India Coordinated Research Project on Sunflower. Edited by D.M. Hegde. Directorate of Oilseeds Research, Hyderabad, India. pp. 9-34.

Tang, S., and Knapp, S.J. 2003. Microsatellites uncover extraordinary diversity in native American land races and wild populations of cultivated sunflower. Theor. Appl. Genet. 106: 990-1003. PMID:12671746.

Tang, S., Yu, J.K., Slabaugh, M.B., Shintani, D.K., and Knapp, S.J. 2002. Simple sequence repeat map of sunflower genome. Theor. Appl. Genet. 105: 1124-1136. doi:10.1007/s00122-002-0989-y. PMID:12582890.

Tang, S., Kishore, V.K., and Knapp, S.J. 2003. PCR multiplexes for a genome wide framework of simple sequence repeat marker loci in cultivated sunflower. Theor. Appl. Genet. 107: 6-19. PMID:12835928. 
Webb, D.M., and Knapp, S.J. 1990. DNA extraction from a previously recalcitrant plant genus. Mol. Biol. Rep. 8: 180-185.

Whelan, E.D.P. 1979. Interspecific hybrids between Helianthus petiolaris Nutt., and $H$. annuus L.: Effect of backcrossing on meiosis. Euphytica, 28: 297-308. doi:10.1007/BF00056586.

Whelan, E.D.P., and Dorrell, D.G. 1980. Interspecific hybrids between Helianthus maximiliani Schrad., and $H$. annuus L.:
Effect of backcrossing on meiosis, anther morphology and seed characteristics. Crop Sci. 20: 29-34.

Yu, J.K., Mangor, J., Thompson, L., Edwards, K.J., Slabaugh, M.B., and Knapp, S.J. 2002. Allelic diversity of simple sequence repeat markers among elite inbred lines in cultivated sunflower. Genome, 45: 652-660. doi:10.1139/g02-025. PMID:12175068. 
Copyright of Genome is the property of NRC Research Press and its content may not be copied or emailed to multiple sites or posted to a listserv without the copyright holder's express written permission. However, users may print, download, or email articles for individual use. 